\title{
INFLUENCE OF OBESITY AND OVERWEIGHT ON TRANSFORMING GROWTH FACTOR BETA 1 LEVELS AND OTHER OXIDATIVE AND CARDIOMETABOLIC PARAMETERS
}

\author{
Eduardo Ottobelli Chielle1, Vanieli Cristina Muller Ogliari ${ }^{1}$ \\ Diego de Carvalho², Aline Pertile Remor ${ }^{2}$
}

\begin{abstract}
Introduction: Obesity is associated with the development of metabolic disorders that can be diagnosed through inflammatory and oxidative biomarkers.
\end{abstract}

Background: This study evaluated the influence of obesity and overweight on serum concentrations of vitamins $C$ and $E$, transforming growth factor beta 1 (TGF- $\beta 1$ ) and cardiometabolic parameters.

Methods: A cross-sectional study was conducted with 169 participants (24 normal weight, 16 overweight and 129 obese). Anthropometric measures and concentrations of vitamins $C$ and $E$, thiobarbituric acid reactive substances (TBARS), TGF- $\beta 1$, lipid profile, glycated hemoglobin $(\mathrm{HbA} 1 \mathrm{c})$, glucose and insulin were determined, and homeostatic model assessment of insulin resistance (HOMA-IR) and insulin sensitivity (IS) were calculated.

Results: Obese and overweight participants showed significantly higher levels of TGF- $\beta 1$, vitamin E, insulin, HbA1c, glucose, cholesterol, low-density lipoprotein cholesterol (LDL-C), triglycerides, HOMA-IR, and TBARS compared with normal weight patients, associated with a significant reduction in IS, high-density lipoprotein cholesterol (HDL-C), and vitamin C.

Conclusions: Obesity and overweight may lead to significant changes in TGF-B1, biochemical and oxidative markers. Increased levels of TGF- $\beta 1$ may promote inflammation and interfere with IS. Reduced concentrations of vitamin $C$ and increased levels of TBARS led to a redox imbalance in obese and overweight patients, suggesting that vitamin $\mathrm{E}$ is not a promising oxidative biomarker since it is lipophilic and its concentration is influenced by body fat. These results may help determine the oxidative and inflammatory pathways related to obesity and its comorbidities.

Keywords: Obesity; vitamins; antioxidants; metabolism

Obesity has increased substantially worldwide in recent years and in all age groups, being thus considered a public health problem. The disease is characterized by the deposition of abnormal or excessive fat in adipose tissue, which must be prevented, mainly for being associated with chronic conditions, such as cardiovascular diseases, dyslipidemia, systemic hypertension, insulin resistance (IR), type 2 diabetes mellitus (DM2) and some types of malignant neoplasms ${ }^{1}$.

Evidence has placed obesity as a chronic subclinical inflammatory condition, associated with dysfunction of the immune system and increase in oxidative stress $^{2}$. A reduction in antioxidant defense systems, or an increased generation of oxidative stress, whether radical or not, may result in oxidative damage in macromolecules of various cellular structures, which, if left unrepaired, will affect the functionality of cells, tissues and organs ${ }^{3}$.

Recent evidence indicates that reactive oxygen species (ROS) could modulate transforming growth factor beta (TGF- $\beta$ ) signaling through different pathways,
Clin Biomed Res. 2018;38(3):273-280

1 Laboratório de Bioquímica Clínica Departamento de Ciências da Vida e Saúde, Universidade do Oeste de Santa Catarina (Unoesc). São Miguel do Oeste, SC, Brasil.

2 Programa de Pós-graduação em Biociência e Saúde, Departamento de Ciências da Vida e Saúde, Universidade do Oeste de Santa Catarina (Unoesc). Joaçaba, SC, Brasil.

Corresponding author: Eduardo Ottobelli Chielle eduardochielle@yahoo.com.br Departamento de Ciências da Vida e Saúde, Universidade do Oeste de Santa Catarina (Unoesc)

Rua Oiapoc, 211. 89900-000, São Miguel do Oeste, SC Brasil. 
including the Smad pathway. TGF- $\beta 1$ increases the production of ROS and suppresses antioxidant enzymes, leading to a redox imbalance, while ROS, in turn, induce/activate TGF- $\beta 1^{4}$. TGF- $\beta 1$ increases the production of ROS by impairing mitochondrial function and inducing NADPH oxidases (NOXs), especially NOX $4^{5}$. TGF- $\beta 1$ also suppresses antioxidant defense, including the synthesis of glutathione, the most abundant intracellular free thiol, and several other antioxidant enzymes, leading to oxidative stress ${ }^{6}$.

One of the ways through which the body neutralizes free radicals is using dietary antioxidants such as a-tocopherol (vitamin E), ascorbic acid (vitamin C), $\beta$-carotene (vitamin A) and phenolic compounds with a predominance of flavonoids and polyflavonoids ${ }^{7}$. Dietary antioxidants inactivate oxidative substances more rapidly in obese than in non-obese individuals. This occurs because the amount of oxidants in obese individuals is higher, with greater need for antioxidants to avoid possible damage ${ }^{8}$.

Vitamins $\mathrm{C}$ and $\mathrm{E}$ play an important physiological role in the reduction of oxidative stress. Vitamin $C$ is a water-soluble antioxidant which neutralizes free radicals, having thus an anticancer role ${ }^{9}$. Vitamin $\mathrm{E}$ prevents or reduces free radical damage in diseases such as arthritis, cancer, cataracts and aging by preventing the action of free radicals on biological membranes ${ }^{10}$.

The use of antioxidant agents may represent a new approach to inhibiting damage caused by the excess of free radicals ${ }^{10}$. Mihalj et al. ${ }^{1}$ demonstrated that vitamin $\mathrm{C}$ reduces blood pressure and reestablishes peripheral vasodilator response in obese children. Weight loss is associated with a reduction in the production of oxidant species and a better antioxidant capacity, favoring a reduction in risk factors and an improvement in comorbidities ${ }^{11}$. Vitamin $\mathrm{E}$ has the antioxidant role of promoting the elimination of free radicals or stimulating the release of other antioxidants, as well as an important participation in glycemic control and prevention of complications of diabetes, especially in $\mathrm{DM} 2^{12}$.

As obesity and overweight are related to decreased levels of vitamins, especially those with antioxidant characteristics, and a redox imbalance, which in turn interferes with the production of TGF- $\beta 1$, this study aimed to evaluate the influence of obesity and overweight on serum concentrations of vitamins $C$ and $E, T G F-\beta 1$, level of lipid peroxidation and cardiometabolic parameters in volunteers with increased body mass index (BMI) compared with volunteers with normal BMI.

\section{METHODS}

\section{Study Population}

Participants were recruited from January to August 2016 in São Miguel do Oeste, Santa Catarina, southern Brazil. The protocol of the study was approved by the Ethics Committee of the University of West of Santa Catarina (UNOESC, no. 219.091), and all participants provided written informed consent. Experiments were performed in 169 volunteers. A total of 24 normal weight individuals with gender-matched healthy volunteers served as a control group (19 females and 5 males). The participants with increased weight were divided into two subgroups, matching for sex, age and BMI, and were enrolled as follows: 1) 16 overweight individuals (12 females and 4 males); 2) 129 obese young individuals (103 females and 26 males). The participants were non-smokers and were not using any medications, as shown in Table 1.

Table 1: Baseline characteristics of the study population.

\begin{tabular}{lcccc}
\hline \multicolumn{4}{c}{ Groups } \\
\hline $\mathrm{N}$ & Normal Weight & Overweight & Obese & p \\
Men/Women & 24 & 16 & 129 \\
Age & $5 / 19$ & $4 / 12$ & $23 / 103$ & \\
BMl $(\mathrm{cm})$ & $42 \pm 15$ & $40 \pm 19$ & $32 \pm 12$ & $<0.001$ \\
Weight $(\mathrm{kg})$ & $21.7 \pm 2.1$ & $27.9 \pm 6.0$ & $30.1 \pm 6.4^{*}$ & $<0.001$ \\
Body fat $(\%)$ & $58.3 \pm 7.4$ & $75.5 \pm 6.3^{* *}$ & $103.4 \pm 22.7^{*}$ & $<0.001$ \\
Body fat $(\mathrm{kg})$ & $22.5 \pm 4.4$ & $30.8 \pm 9.5^{* *}$ & $43.5 \pm 28.8^{*}$ & $<0.001$ \\
NC $(\mathrm{cm})$ & $13.0 \pm 2.6$ & $25.5 \pm 18.4^{* *}$ & $42.3 \pm 12.1^{*}$ & $<0.001$ \\
WC $(\mathrm{cm})$ & $31.2 \pm 2.3$ & $33.0 \pm 3.4$ & $36.6 \pm 4.4^{*}$ & $<0.001$ \\
HC $(\mathrm{cm})$ & $70.8 \pm 7.1$ & $85.0 \pm 8.4$ & $112.7 \pm 13.4^{*}$ & $<0.001$ \\
DBP $(\mathrm{mmHg})$ & $94.9 \pm 4.3$ & $102.0 \pm 4.3$ & $121.0 \pm 13.9^{*}$ & $<0.001$ \\
SBP $(\mathrm{mmHg})$ & $10.8 \pm 1.1$ & $12.0 \pm 5.7$ & $13.2 \pm 1.9^{*}$ & $<0.001$
\end{tabular}

Data are expressed as mean \pm standard deviation or median (interquartile ranges). Data were analyzed using one-way analysis of variance (ANOVA), followed by Tukey's or Kruskal-Wallis test and then by Dunn's multiple comparison test. BMl: Body Mass Index; NC: Neck Circumference; WC: Waist Circumference; HC: Hip Circumference; DBP: Diastolic Blood Pressure; SBP: Systolic Blood Pressure. * $p<0.001$, obese group compared with normal weight group. ${ }^{* *} p<0.001$, overweight group compared with normal weight group. 


\section{Anthropometric measurement}

All measurements were performed at the Anthropometry Laboratory at the University of West of Santa Catarina, São Miguel do Oeste (Table 1). Standing height $(\mathrm{H}, \mathrm{cm})$ was measured to the nearest $0.1 \mathrm{~cm}$ using a wall-mounted stadiometer (Charder model HM-210D). Weight (W, kg) was measured to the nearest $0.1 \mathrm{~kg}$ using a calibrated electronic scale (Toledo model 2124). BMI was calculated as $\mathrm{W} / \mathrm{H}^{2}\left(\mathrm{~kg} / \mathrm{m}^{2}\right)$. Waist circumference (WC), neck circumference $(\mathrm{NC})$ and hip circumference $(\mathrm{HC})$ were measured in centimeters with a flexible tape to the nearest $0.1 \mathrm{~cm}$. For WC the tape was applied above the iliac crest with the person standing with the abdomen relaxed, arms extended along sides and feet together. For NC the participant remained in the same position and the tape was placed around the neck over the hyoid bone. Body fat percentage and body fat mass were determined by bioimpedance analysis (Biodynamics Model 450). Systolic and diastolic pressure (SBP, DBP) were measured after the participant was sitting and resting for 10 minutes with a digital apparatus and were expressed in $\mathrm{mmHg}$. All measurements were performed on the left side of the body, according to standardized procedures described by Lourie and Weiner ${ }^{13}$. During the anthropometric measurements, all participants were barefoot and wearing appropriate clothes.

\section{Indices and classifications}

According to the World Health Organization, underweight is defined as $\mathrm{BMI}<18.5 \mathrm{~kg} / \mathrm{m}^{2}$, normal weight as BMI $18.5-24.9 \mathrm{~kg} / \mathrm{m}^{2}$, overweight as BMI $25-29.9 \mathrm{~kg} / \mathrm{m}^{2}$, and obesity as $\mathrm{BMI} \geq 30 \mathrm{~kg} / \mathrm{m}^{214}$, all without comorbidities. According to Gallagher et al..$^{15}$, body fat percentage $\geq 20 \%$ (men) and $\geq 33 \%$ (women) are the cutoff points adopted to define fatness, corresponding to overweight classification using $\mathrm{BMI}$ in a population of young adults. According to the National Institute for Health and Clinical Excellence guidelines, WC $\geq 102 \mathrm{~cm}$ (men) and $\geq 88 \mathrm{~cm}$ (women) are prerequisite risk factors for the diagnosis of metabolic syndrome, as well as waist-to-stature ratio (WSR) $\geq 0.5$ for both men and women ${ }^{16}$.

\section{Laboratory methods}

Blood samples were collected after 10-12-hour fasting by venipuncture and placed in tubes with ethylenediaminetetraacetic acid (EDTA) or without anticoagulant with separator gel to obtain the serum. The tubes without anticoagulant were centrifuged for 10 minutes at $6000 \mathrm{rpm}$. The serum was separated and placed in amber containers to prevent metabolic breakdown.

\section{Biochemical and hormonal measures}

Insulin concentration was determined by electrochemiluminescence immunoassay using Elecsys 2010 analyzer (Roche Diagnostics ${ }^{\circledR}$ ). IR index was calculated by homeostatic model assessment of IR (HOMA-IR) as follows: (fasting insulin $\mathrm{mIU} / \mathrm{L}) \times$ (fasting glucose $\mathrm{mg} / \mathrm{dL}$ )/22.5. For evaluation of insulin sensitivity (IS), the quantitative insulin sensitivity check index (QUISCI) was used. Glucose, cholesterol, triglycerides and high-density lipoprotein cholesterol (HDL-c) concentrations were determined using kits (Labtest Diagnostics ${ }^{\circledR}$ ). Low-density lipoprotein cholesterol (LDL-c) was calculated using the Friedewald formula. $\mathrm{HbA}_{1 \mathrm{c}}$ was measured by high performance liquid chromatography (HPLC) (Tosoh 2.2 Plus A1C, Tosoh Corporation, Tokyo, Japan), a method certified by the National Glycohemoglobin Standardization Program and standardized by the International Federation of Clinical Chemistry, expressed in \%. Lipid peroxidation was estimated by measuring thiobarbituric acid reactive substances (TBARS) according to the method of Lapenna et al. ${ }^{17}$. The reaction product was measured spectrophotometrically at $532 \mathrm{~nm}$ and the results were expressed in $\mathrm{nmol} / \mathrm{L}$. Vitamins $\mathrm{C}$ and $\mathrm{E}$ were measured by enzyme-linked immunosorbent assay (ELISA) (ABCAM - Ascorbic Acid Assay Kit ${ }^{\circledR}$ and Rac Beta - Tocopherol Assay Kit ${ }^{\circledR}$ ) and were expressed in $\mathrm{nmol} / \mu \mathrm{L}$. TGF- $\beta 1$ was measured by ELISA (ABCAM - ab100647). This assay employs a specific antibody for human TGF- $\beta 1$ coated on a 96 -well plate. Standards and samples are pipetted into the wells and TGF- $\beta 1$ present in the sample is bound to the wells by the immobilized antibody. The wells are washed and biotinylated anti-human TGF- $\beta 1$ antibody is added. After washing away unbound biotinylated antibody, horseradish peroxidase (HRP)-conjugated streptavidin is pipetted to the wells. The wells are washed again, a 3,3',5,5'-tetramethylbenzidine (TMB) substrate solution is added to the wells and color develops in proportion to the amount of bound TGF- $\beta 1$. The color of the stop solution changes from blue to yellow, and the intensity of the color is measured at $450 \mathrm{~nm}$ and expressed in $\mathrm{ng} / \mathrm{mL}$.

\section{Statistical Analysis}

The Kolmogorov-Smirnov test was used to examine the distribution of variables. Comparisons of baseline data between the groups were performed using one-way analysis of variance (ANOVA) followed by Tukey's test or Kruskal-Wallis test and then by Dunn's multiple comparison test, in order to determine statistical differences between the BMI groups and gender. Statistical significance was defined as $p<0.05$. The data were analyzed using Statistica 6.0 software (StatSoft, Tulsa, OK, USA). 


\section{RESULTS}

\section{General Characteristics Of The Study Population}

Baseline characteristics of study participants are described in Table 1. In relation to SBP, DBP, weight, $\mathrm{BMI}, \mathrm{NC}, \mathrm{HC}, \mathrm{WC}$, body fat percentage and body fat mass, the obese group showed a significant increase $(p<0.0001)$ when compared with the normal weight and the overweight groups.

\section{Laboratory tests}

The results of laboratory tests are presented in Table 2 and Figures 1-4. The obese group showed a significant increase in insulin, glucose, $\mathrm{HbA}_{1 \mathrm{c}}$,
HOMA-IR, cholesterol, LDL-c, triglycerides $(p<0.001)$, as well as TGF- $\beta 1$, vitamin E and TBARS $(p<0.001)$ when compared with the normal weight group. In the obese group there was a significant reduction in IS, HDL-c and vitamin $C(p<0.001)$ when compared with the normal weight group. Moreover, the overweight group showed a significant increase $(p<0.001)$ in cholesterol, LDL-c, triglycerides, TBARS, vitamin E and TGF- $\beta 1$, and a significant reduction $(p<0.001)$ in HDL-C and vitamin $C$ when compared with the normal weight group. No significant differences between genders were observed.

Table 2: Biochemical concentrations of study groups.

\begin{tabular}{lcccc}
\hline \multicolumn{5}{c}{ Groups } \\
\hline & Normal Weight & Overweight & Obese & p \\
\hline Triglycerides $(\mathrm{mg} / \mathrm{dL})$ & $78.2 \pm 22.7$ & $93.6 \pm 61.5^{* *}$ & $137.9 \pm 84.5^{*}$ & $<0.001$ \\
Cholesterol $(\mathrm{mg} / \mathrm{dL})$ & $132(125-163)$ & $177(140-225)^{* *}$ & $182(155-211)^{*}$ & $<0.001$ \\
HDL-c $(\mathrm{mg} / \mathrm{dL})$ & $52(45-59)$ & $41(36-55)^{* *}$ & $41(34-48)^{*}$ & $<0.001$ \\
LDL-c $(\mathrm{mg} / \mathrm{dL})$ & $66(52-92)$ & $113(87-159)^{\star *}$ & $120(90-141)^{*}$ & $<0.001$ \\
Glucose $(\mathrm{mg} / \mathrm{dL})$ & $78 \pm 6.0$ & $80 \pm 17$ & $92 \pm 32^{*}$ & $<0.001$ \\
Insulin $(\mu \mathrm{Ul} / \mathrm{mL})$ & $7.4 \pm 3.0$ & $9.6 \pm 5.1$ & $24.0 \pm 14.5^{*}$ & $<0.001$ \\
HbA $(\%)$ & $5.4 \pm 0.3$ & $5.7 \pm 0.8$ & $6.1 \pm 1.3^{*}$ & $<0.001$ \\
eAG & $117 \pm 4.2$ & $127 \pm 28$ & $132 \pm 41$ & 0.13 \\
HOMA-IR & $1.4 \pm 0.6$ & $1.9 \pm 1.1$ & $5.9 \pm 5.5^{*}$ & $<0.001$ \\
IS & $0.36 \pm 0.02$ & $0.35 \pm 0.03$ & $0.30 \pm 0.02^{*}$ & $<0.001$ \\
\hline
\end{tabular}

Data are expressed as mean \pm standard deviation or median (interquartile ranges). Data were analyzed using one-way analysis of variance (ANOVA), followed by Tukey's or Kruskal-Wallis test and then by Dunn's multiple comparison test. HDL-c: high-density lipoprotein cholesterol; LDL-C: low-density lipoprotein cholesterol; $\mathrm{HbA}_{1}$ : glycated hemoglobin; eAG: estimated average glucose; HOMA-IR: homeostatic model assessment of insulin resistance; IS: insulin sensitivity. ${ }^{*} p<0.001$, obese group compared with normal weight group. ${ }^{* *} p<0.001$, overweight group compared with normal weight and overweight groups.

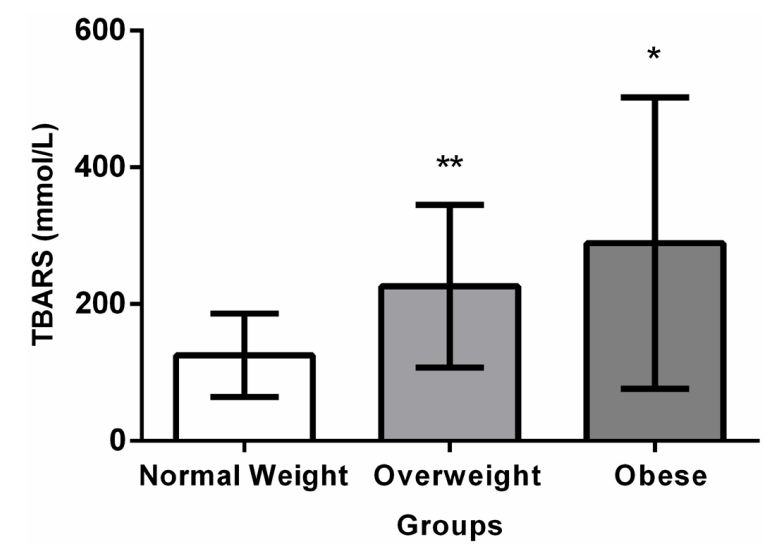

Figure 1: Serum concentration of thiobarbituric acid reactive substances (TBARS) in the study groups. Data are expressed as mean \pm standard deviation. Data were analyzed using one-way analysis of variance (ANOVA), followed by Tukey's test. ${ }^{*} p<0.001$, obese group compared with normal weight group. ${ }^{* *} p<0.001$, overweight group compared with the normal weight and the overweight groups.

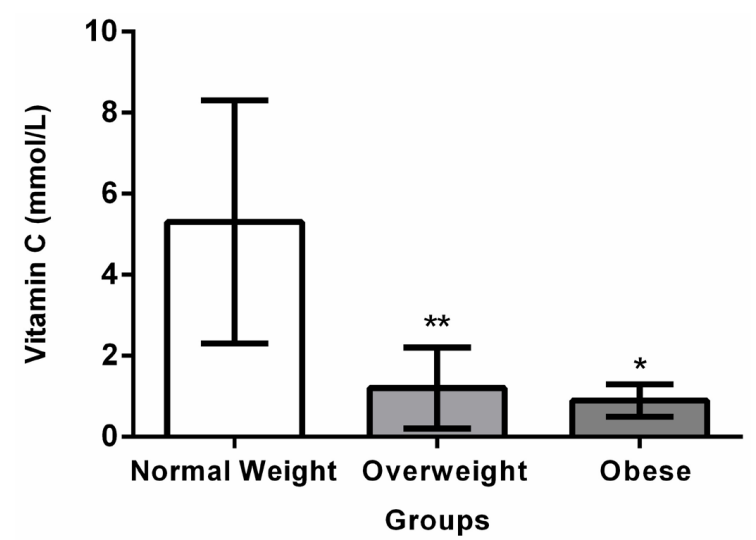

Figure 2: Serum concentration of vitamin $C$ in the study groups. Data are expressed as mean \pm standard deviation. Data were analyzed using one-way analysis of variance (ANOVA), followed by Tukey's test. * $p<0.001$, obese group compared with normal weight group. ${ }^{* *} p<0.001$, overweight group compared with normal weight and overweight groups. 


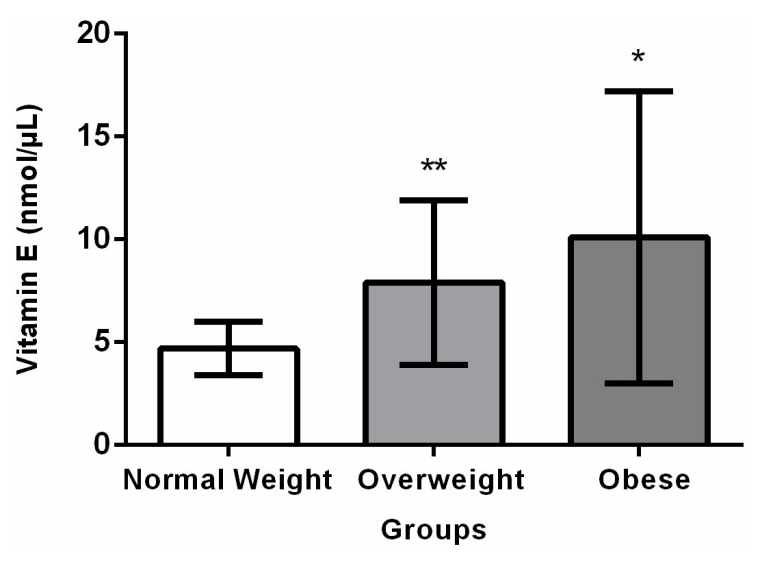

Figure 3: Serum concentration of vitamin $E$ in the study groups. Data are expressed as mean \pm standard deviation. Data were analyzed using one-way analysis of variance (ANOVA), followed by Tukey's test. * $p<0.001$, obese group compared with normal weight group. ${ }^{* *} p<0.05$, overweight group compared with normal weight group.

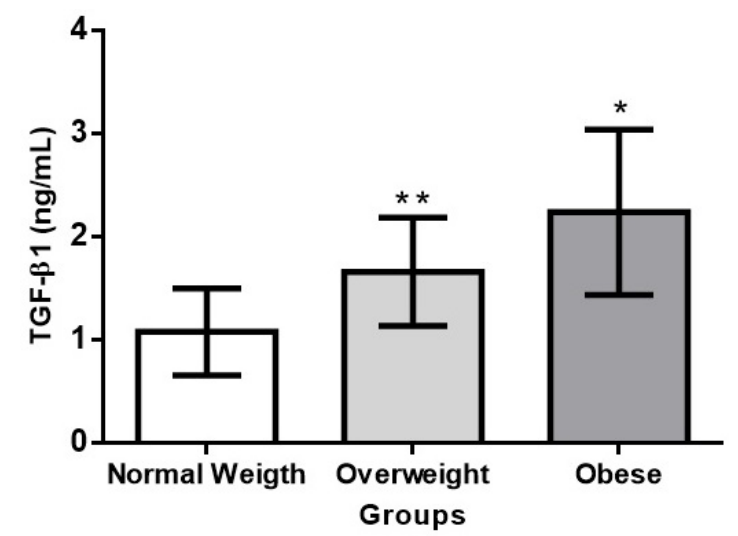

Figure 4: Serum concentration of transforming growth factor beta 1 (TGF- $\beta 1$ ) in the study groups. Data are expressed as mean \pm standard deviation. Data were analyzed using one-way analysis of variance (ANOVA), followed by Tukey's test. ${ }^{*} p<0.001$, obese group compared with normal weight group. ${ }^{* *} p<0.001$, overweight group compared with normal weight group.

\section{DISCUSSION}

Multiple mechanisms may contribute to the development of obesity-related comorbidities, including abnormal production of cytokines, aberrant oxidative stress and dysregulated proinflammatory response in tissues of the muscles and the liver ${ }^{2}$. Cytokines and inflammatory markers could mediate the facilitating effect of obesity on the appearance of its comorbidities such as IR, DM2 and cardiovascular disease ${ }^{18}$.

In the present report, we examined the influence of obesity and overweight on serum concentrations of
TGF- $\beta 1$, vitamins $C$ and $E$, TBARS and cardiometabolic parameters. The results indicate that TGF- $\beta 1$, vitamin $E$ and TBARS are increased and vitamin $C$ is decreased in obese and overweight adults (Figures 4, 3, 1 and 2, respectively) when compared with individuals with normal weight.

TGF- $\beta 1$ is a type of cytokine that exhibits potent immunoregulatory and anti-inflammatory properties ${ }^{19}$. It also correlates with obesity-induced $\mathrm{IR}^{3}$, and TGF- $\beta /$ Smad3 signaling pathway plays a key role in the development of IR as shown in genetically obese mice ${ }^{20}$. Within this context, an elevation in TGF- $\beta$ levels may carry relevant pathophysiological implications. In fact, TGF- $\beta 1$ potently stimulates monocyte chemotaxis and endothelial transmigration and promotes smooth muscle cell proliferation and migration by up-regulating platelet-derived growth factor gene expression ${ }^{21}$. These represent early events in atherosclerosis development. TGF- $\beta 1$ also induces PAl-1 both in live and cultured adipocytes ${ }^{22}$, as well as in other tissues ${ }^{23}$. In addition, together with increased BMI, there was greater serum accumulation of triglycerides, total cholesterol and especially LDL-c, suggesting that the elevated secretion of TGF- $\beta 1$ in obese conditions may affect lipid metabolism in obese and overweight adults, triggering the production of LDL-c in liver cells and degrading the LDL-c receptor in the liver. Furthermore, this cytokine has atherogenic potential by increasing the expression of intercellular adhesion molecule- 1 and anti-vascular- 1 in vascular endothelial cells and increasing nuclear factor kappa beta (NF-k $\beta$ ) activity, a flare gun for induction of these adhesion molecules ${ }^{24}$.

It has been shown that TGF- $\beta / \mathrm{Smad} 3$ signaling is an important regulator of insulin gene transcription and $\beta$-cell function, and TGF- $\beta$ signaling represses insulin gene transcription ${ }^{25}$. Also, TGF- $\beta$ signaling regulates glucose tolerance ${ }^{26}$. In fact, concomitantly with the increase in TGF- $\beta 1$ in proportion to the increase in $B M I$, we observed a significant increase in insulin, glucose, $\mathrm{HbA}_{1 \mathrm{c}}$ and $\mathrm{HOMA}-\mathrm{IR}$ levels and a significant decrease in IS, suggesting that this cytokine could play an important role in the development of IR in patients with excess weight. Previous studies have shown that TGF- $\beta$ contributes to the development of IR in pregnant women ${ }^{27-29}$.

Another relevant point is that TGF- $\beta 1$ increases the production of ROS by impairing mitochondrial function and inducing NOXs, especially NOX4, a non-phagocytic NOX expressed by many different types of cells. TGF- $\beta$ also suppresses the antioxidant system, including the synthesis of glutathione, the most abundant intracellular free thiol and an important antioxidant, and several other antioxidant enzymes, leading to oxidative stress or redox imbalance. 
This redox imbalance in turn induces/activates TGF- $\beta 1^{18}$.

This study also evaluated the concentration of vitamins $C$ and $E$, which have an important antioxidant function. With the increase in BMl there was a significant decrease in vitamin $\mathrm{C}$ levels (Figure 2), thus decreasing the capacity of the obese and the overweight organism to neutralize free radicals, while increasing ROS, lipid peroxidation and TBARS concentration. As vitamin $\mathrm{C}$ is a water-soluble vitamin, with the increase in body weight and concomitant reduction in the relation between lean mass and fat mass, there is a reduction in the water phase to the lipid phase of the body and thus a decrease in vitamin $C$, exposing the cells to the deleterious effects of oxidative stress ${ }^{30}$.

Contrasting with this finding there was a significant increase in vitamin E concentration together with the increase in BMI (Figure 3). This can be explained by the fact that this vitamin is liposoluble ${ }^{31}$. As obese and overweight patients showed larger amounts of circulating lipids in this study, this vitamin remains in circulation for a longer period when submitted to higher serum lipid concentrations. This is probably related to the slower catabolism of lipoproteins and thus the higher level of serum lipids and greater amount of circulating vitamin $E^{32}$. We believe that the determination of vitamin $\mathrm{E}$ may not be a good immediate antioxidant indicator in obese and overweight patients, as it is related to the plasma concentration of lipids. Thus, a normal amount of vitamin $E$ would be a reflection of antioxidant activity, but related to the accumulation of serum lipids, especially because we found increased TBARS in obese and overweight patients when compared with patients with normal BMI.

\section{CONCLUSION}

The most important finding of the study was that obesity and excess weight may lead to significant changes in TGF- $\beta 1$ levels and biochemical and oxidative markers. Increased TGF- $\beta 1$, resulting from infiltration and activation of macrophages in adipose tissue, can promote inflammation and impairment of IS, therefore having a critical role in the pathogenesis of IR, dyslipidemia and atherosclerosis. Moreover, TGF- $\beta 1$ increased ROS production and suppressed the antioxidant system, which promotes reduction of vitamin C and increase in TBARS concentration, leading to redox imbalance in obese and overweight patients. In addition, it is believed that vitamin E may not be an oxidative biomarker in patients with excess weight associated with dyslipidemia because it has lipophilic characteristics and its concentration is closely related to the increase in serum lipids. The present results could help determine the pathways involved in obesity-related inflammation and its comorbidities. They may also play a role in identifying new inflammatory markers, especially for the obese population, and thus contribute to preventing the network of inflammatory and oxidative complications related to obesity.

\section{Acknowledgements}

The present study had the financial support of the Article 170 - Constitution of the State of Santa Catarina. We wish to thank the University of West of Santa Catarina (UNOESC), SC, Brazil, for supporting this study. Also, we thank all the volunteers who participated in this study.

\section{Conflicts of Interest}

The authors declare no conflicts of interest.

\section{REFERENCES}

1. Mihalj M, Tadzic R, Vcev A, Rucevic $\mathrm{S}$, Drenjancevic I. Blood pressure reduction is associated with the changes in oxidative stress and endothelial activation in hypertension, regardless of antihypertensive therapy. Kidney Blood Press Res. 2016;41(6):721-35. http:// dx.doi.org/10.1159/000450562. PMid:27788510.

2. Ottobelli Chielle E, Souza WM, Silva TP, Moresco RN, Moretto MB. Adipocytokines, inflammatory and oxidative stress markers of clinical relevance altered in young overweight/obese subjects. Clin
Biochem. 2016;49(7-8):54853. http://dx.doi.org/10.1016/j. clinbiochem.2016.01.003. PMid:26794633.

3. Romano M, Guagnano MT, Pacini G, Vigneri S, Falco A, Marinopiccoli $M$, et al. Association of inflammation markers with impaired insulin sensitivity and coagulative activation in obese healthy women. $J$ Clin Endocrinol Metab. 2003:88(11):53216. http://dx.doi.org/10.1210/jc.2003030508 . PMid: 14602768.

4. Liu RM, Desai LP. Reciprocal regulation of TGF- $\beta$ and reactive oxygen species: a perverse cycle for fibrosis. Redox Biol. 2015;6:565-

77. http://dx.doi.org/10.1016/j. redox.2015.09.009. PMid:26496488.

5. Handy DE, Loscalzo J. Responses to reductive stress in the cardiovascular system. Free Radic Biol Med 2016;109: 114-24.

6. Tang $\mathrm{ZH}$, Zhang $\mathrm{C}$, Cheng $\mathrm{P}$, Sun $\mathrm{HM}$ Jin Y, Chen YJ, et al. Glutathione-STransferase Polymorphisms (GSTM1, GSTT1 and GSTP1) and Acute Leukemia Risk in Asians: a Metaanalysis. Asian Pac J Cancer Prev. 2014;15(5):2075-81. http://dx.doi. org/10.7314/APJCP.2014.15.5.2075 PMid:24716937. 
7. Sies $\mathrm{H}$. Hydrogen peroxide as a central redox signaling molecule in physiological oxidative stress: Oxidative stress. Redox Biol. 2017;11:613-9. http://dx.doi. org/10.1016/j.redox.2016.12.035. PMid:28110218.

8. Olusi SO. Obesity is an independent risk factor for plasma lipid peroxidation and depletion of erythrocyte cytoprotectic enzymes in humans. Int J Obes Relat Metab Disord. 2002;26(9):1159-64. http:// dx.doi.org/10.1038/sj.ijo.0802066. PMid:12187391.

9. Gong EY, Shin YJ, Hwang IY, Kim JH, Kim SM, Moon JH, et al. Combined treatment with vitamin $\mathrm{C}$ and sulindac synergistically induces p53- and ROS-dependent apoptosis in human colon cancer cells. Toxicol Lett. 2016;258:126-33. http://dx.doi. org/10.1016/j.toxlet.2016.06.019. PMid:27339904.

10. Herndon JH JR, Jiang LI, Kononov T, Fox T. Open label clinical trial to evaluate the efficacy and tolerance of a retinol and Vitamin $\mathrm{C}$ facial regimen in women with mild-to-moderate hyperpigmentation and photodamaged facial skin. J Drugs Dermatol. 2016;15(4):476-82. PMid:27050703.

11. Feingold K, Brinton EA, Grunfeld C. The Effect of endocrine disorders on lipids and lipoproteins In: De Groot LJ Chrousos G, Dungan K, Feingold KR, Grossman A, Hershman JM, Koch C, Korbonits M, McLachlan R, New M, Purnell J, Rebar R, Singer F, Vinik A, editors. Endotext. South Dartmouth: MDText.com, Inc.; 2000-2017.

12. Ramezani A, Koohdani F, Djazayeri A, Nematipour E, Keshavarz SA, Saboor Yaraghi AA, et al. Effects of administration of omega-3 fatty acids with or without vitamin $\mathrm{E}$ supplementation on adiponectin gene expression in PBMCs and serum adiponectin and adipocyte fatty acid-binding protein levels in male patients with CAD. Anatol J Cardiol. 2015;15(12):981-9. http:// dx.doi.org/10.5152/akd.2015.5849. PMid:25880054.

13. Lourie JA, Weiner JS. Practical human biology. London: Academic Press; 1981.

14. James PT, Leach R, Kalamara E, Shayeghi M. The worldwide obesity epidemic. Obes Res.
2001;9(S11 Suppl 4):S228-33. http:// dx.doi.org/10.1038/oby.2001.123. PMid:11707546.

15. Gallagher D, Heymsfield SB, Heo M, Jebb SA, Murgatroyd PR, Sakamoto $Y$. Healthy percentage body fat ranges: an approach for developing guidelines based on body mass index. Am J Clin Nutr. 2000;72(3):694701. http://dx.doi.org/10.1093/ ajcn/72.3.694. PMid:10966886.

16. Ashwell M, Hsieh SD. Six reasons why the waist-to-height ratio is a rapid and effective global indicator for health risks of obesity and how its use could simplify the international public health message on obesity. Int J Food Sci Nutr. 2005;56(5):303-7. http://dx.doi. org/10.1080/09637480500195066. PMid:16236591.

17. Lapenna D, Ciofani G, Pierdomenico SD, Giamberardino MA, Cuccurullo F. Reaction conditions affecting the relationship between thiobarbituric acid reactivity and lipid peroxides in human plasma. Free Radic Biol Med. 2001;31(3):331-5. http://dx.doi. org/10.1016/S0891-5849(01)00584-6. PMid:11461770.

18. Broadbent J, Fuller-Tyszkiewicz M, Dennerstein M, Greenwood J, Hancock N, Thavapalan N, et al. Doing the counter-regulation shuffle: The importance of flexibility and hunger for predicting food consumption following a preload. Obes Res Clin Pract. 2016;10(6):61723. http://dx.doi.org/10.1016/j. orcp.2016.05.006. PMid:27262185.

19. Jones RL, Stoikos C, Findlay JK, Salamonsen LA. TGF-b superfamily expression and actions in the endometrium and placenta. Reproduction. 2006;132(2):217-32. http://dx.doi.org/10.1530/rep.1.01076. PMid:16885531.

20. Tsurutani Y, Fujimoto M, Takemoto $\mathrm{M}$, Irisuna $\mathrm{H}$, Koshizaka M, Onishi $S$, et al. The roles of transforming growth factor- $\beta$ and Smad3 signaling in adipocyte differentiation and besity. Biochem Biophys Res Commun. 2011;407(1):68-73. http://dx.doi. org/10.1016/j.bbrc.2011.02.106. PMid:21356196.

21. Blobe GC, Schiemann WP, Lodish HF. Role of transforming growth Factor $\beta$ in human disease. N Engl J Med. 2000;342(18):1350-8. http://dx.doi. org/10.1056/NEJM200005043421807. PMid:10793168.
22. Samad F, Yamamoto K, Pandey M, Loskutoff DJ. Elevated expression of transforming growth factor-beta in adipose tissue from obese mice. Mol Med. 1997;3(1):37-48. PMid:9132278.

23. Chen $Y Q$, Sloan-Lancaster J, Berg DT, Richardson MA, Grinnell B, TsengCrank J. Differential mechanisms of plasminogen activator inhibitor-1 gene activation by transforming growth factor-beta and tumor necrosis factoralpha in endothelial cells. Thromb Haemost. 2001;86(6):1563-72. http:// dx.doi.org/10.1055/s-0037-1616763. PMid:11776328.

24. Ort T, Arjona AA, MacDougall JR, Nelson PJ, Rothenberg ME, Wu $\mathrm{F}$, et al. Recombinant human FIZZ3/ resistin stimulates lipolysis in cultured human adipocytes, mouse adipose explants, and normal mice. Endocrinology. 2005;146(5):2200-9. http://dx.doi.org/10.1210/en.20041421. PMid:15705777.

25. Lin HM, Lee JH, Yadav H, Kamaraju AK, Liu E, Zhigang D, et al. Transforming growth factor- I Smad3 signaling regulates insulin gene transcription and pancreatic islet -cell function. $J$ Biol Chem. 2009;284(18):12246-57. http:// dx.doi.org/10.1074/jbc.M805379200. PMid:19265200.

26. Yadav H, Quijano C, Kamaraju AK, Gavrilova O, Malek R, Chen W, et al. Protection from obesity and diabetes by blockade of TGF- $\beta /$ Smad3 Signaling. Cell Metab. 2011;14(1):6779. http://dx.doi.org/10.1016/j. cmet.2011.04.013. PMid:21723505.

27. Slater M, Murphy CR. Transforming growth factors $\alpha$ and $\beta-1$ are coexpressed in the uterine epithelium during early pregnancy. Cell Tissue Res. 2000;300(2):315-20. http:// dx.doi.org/10.1007/s004419900139. PMid:10867826.

28. Ayatollahi M, Geramizadeh B, Samsami A. Transforming growth factor Beta-1 influence on fetal allografts during pregnancy. Transplant Proc. 2005;37(10):46034. http://dx.doi.org/10.1016/j. transproceed.2005.11.023. PMid:16387180.

29. Sotoodeh Jahromi A, Sanie MS, Yusefi A, Zabetian H, Zareian P, Hakimelahi $\mathrm{H}$, et al. Association of tumor growth Factor- $\beta$ and Interferon-y serum levels with insulin resistance in normal pregnancy. Glob 
J Health Sci. 2015;8(6):25-32. http:// dx.doi.org/10.5539/gjhs.v8n6p25. PMid:26755467.

30. Hosseini B, Saedisomeolia A, AllmanFarinelli M. Association between antioxidant intake/status and obesity: a systematic review of observational studies. Biol Trace Elem Res. 2016;175(1):287-97. PMid:27334437.
31. Chai W, Conroy SM, Maskarinec G, Franke AA, Pagano IS, Cooney RV. Associations between obesity and serum lipid-soluble micronutrients among premenopausal women. Nutr Res. 2010;30(4):227-32. http://dx.doi. org/10.1016/j.nutres.2010.04.006.

PMid:20534324.
32. Traber MG, Leonard SW, Bobe G, Fu X, Saltzman E, Grusak MA, et al. Tocopherol disappearance rates from plasma depend on lipid concentrations: studies using deuterium-labeled collard greens in younger and older adults. $\mathrm{Am} \mathrm{J}$ Clin Nutr. 2015;101(4):752-9. http:// dx.doi.org/10.3945/ajcn.114.100966. PMid:25739929.

Received: Jan 5, 2018 Accepted: Jun 24, 2018 